\title{
Potential Impact of UWWT Effluent Discharges on Ruditapes decussatus: An Approach Using Biomarkers
}

Sofia Silva ${ }^{1,{ }^{\dagger}}$, Alexandra Cravo ${ }^{2,{ }^{+}}$, João Rodrigues ${ }^{3,{ }^{\dagger}}$, Cátia Correia ${ }^{2}$, Cristina M. M. Almeida ${ }^{1,4,{ }^{+}, *}$

1. Laboratory of Bromatology and Water Quality, Faculty of Pharmacy, University of Lisbon, Av. Prof. Gama Pinto, 2, 1649-003 Lisboa, Portugal; E-Mails: sofia.silva-e@adp.pt; calmeida@ff.ulisboa.pt

2. Centro de Investigação Marinha e Ambiental (CIMA), Universidade do Algarve, Campus de Gambelas, FCT -Edifício 7, 8005-139 Faro, Portugal; E-Mails: acravo@ualg.pt; cfcorreia@ualg.pt

3. Center for Neuroscience and Cell Biology (CNC), University of Coimbra, Rua Larga, Faculty of Medicine, 3004-504 Coimbra, Portugal; E-Mail: joao.e.a.rodrigues@gmail.com

4. iMed.UL (Institute for Medicines and Pharmaceutical Sciences, Portugal); Faculty of Pharmacy, University of Lisboa, Av. Prof. Gama Pinto, 2, 1649-003 Lisboa, Portugal

+ These authors contributed equally to this work.

* Correspondence: Cristina M. M. Almeida; E-Mail: calmeida@ff.ulisboa.pt

Academic Editor: Amanda Laca

Special Issue: Environmental Impact Assessment

Adv Environ Eng Res

2021, volume 2, issue 2

doi:10.21926/aeer.2102015
Received: April 09, 2021

Accepted: May 31, 2021

Published: June 19, 2021

\begin{abstract}
The use of biomarkers in bivalves has gained significance as a reliable method for the assessment of the presence and effect of contaminants in aquatic ecosystems. However, it is important to note that the biomarkers respond not only to contaminant loadings and bioavailability but also to environmental stress. Therefore, the association between biomarkers and contamination/pollution should be conducted cautiously as the environmental factors also affect their response. These factors should be integrated into the assessment of the response of the biomarkers. The potential impact of effluents from an
\end{abstract}

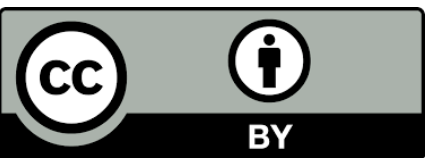

(c) 2021 by the author. This is an open access article distributed under the conditions of the Creative Commons by Attribution License, which permits unrestricted use, distribution, and reproduction in any medium or format, provided the original work is correctly cited. 
urban wastewater treatment plant (UWWTP) on the Ruditapes decussatus clam specimens located $1.5 \mathrm{Km}$ away in a surrounding area was evaluated. After one month of exposure, three biomarkers were analyzed, namely lipid peroxidation (LPO), acetylcholinesterase (AChE) and electron transport system (ETS). These parameters were also determined for a control group purchased from a local nursery, which had no influence from UWWTP, in order to compare the results obtained from both groups. The in situ physicochemical characterization of the exposure site (temperature, salinity, $\mathrm{pH}$ and dissolved oxygen) was evaluated together with nutritional parameters, morphometric measurements and condition index. The biochemical analysis showed that the activity levels of AChE fluctuated from 4.0 to $4.6 \mathrm{nmol} / \mathrm{min}$ g protein and that of LPO from 101.5 to $248.9 \mathrm{nmol}$ MDA/g protein. Also, the ETS activity levels were in the range of 27.2 to $30.2 \mathrm{nmol} \mathrm{O}_{2} / \mathrm{min}$ g protein. The lipid peroxidation was found to be the most responsive biomarker toward the damage caused by environmental conditions on the clams.

\section{Keywords}

Ruditapes decussatus; biomarkers; lipid peroxidation; acetylcholinesterase; electron transport system

\section{Introduction}

The environmental monitoring of air, soils, and aquatic ecosystems is of great importance. Several methods have been implemented to address this concern, either by the direct measurement of the level of potential contaminants or using biological surrogates for the simultaneous estimation of the bioaccumulated concentrations and effects of the substances [1]. In this context, one of the most significant approaches is the use of biomarkers on wildlife communities called sentinel species, which ultimately leads to the early identification and warning of any potential risks to the human population [2, 3]. Biomarkers are valuable tools that can be used to determine the interactions between biological systems and potential contaminants (chemical, physical or biological) [4] by measuring the appropriate biological response at molecular, cellular, biochemical, physiological or behavioral levels [5]. Among the biological effects of the pollutants, biochemical changes occur more quickly and sensitively. Therefore, biomarkers allow the integrated measurement of bioavailable contaminants causing biochemical responses [6].

These biomonitoring methods evaluate not only the presence, but the more significant response of the organisms to these contaminants by the assessment of biomarkers, i.e., parameters that reflect their effects at a molecular, cellular, organ, and organism level. This approach does not replace chemical monitoring or population studies but integrates them in determining the toxic effects of the pollutants even under trace or sub-lethal concentrations [7].

Several systems have been described for the classification of biomarkers. According to the World Health Organization [4], biomarkers are divided into three categories: exposure, effect, and susceptibility. A more descriptive approach was established by van der Oost et al. [8], who classified biomarkers into ten different categories on the basis of the type of monitored response as follows: biotransformation enzymes, oxidative stress, biotransformation products, amino acids and proteins, 
hematological, immunological, reproductive and endocrine, neuromuscular, genotoxic, physiological and morphological types.

The selection of each biomarker or group of biomarkers is specific to some organisms or exposure conditions. Some of the most frequently used biomarkers for the detection of marine pollution through the local biota analysis are cytochrome P450A1 enzymatic induction, metallothioneins (proteins), DNA integrity, acetylcholinesterase activity, electron transport system activity, and lipid peroxidation [9-11]. The latter three biomarkers were selected for this study.

Lipid peroxidation (LPO) is an oxidative stress biomarker considered to have great potential for the assessment of environmental risks [12]. LPO is attributed to the presence of some pollutants, such as polycyclic aromatic hydrocarbons (PAHs), metals, polychlorobiphenyls (PCBs), and pharmaceuticals [13]. Among them, caffeine has been found [9] to attack the membrane lipids and initiate an autocatalytic chain reaction that leads to the oxidation of the polyunsaturated fatty acids that constitute the membrane $[8,14]$. The degradation of the lipid membrane results in the formation of peroxides and aldehydes. The extent of this process is evaluated by the quantification of one of the byproducts of lipid degradation, namely malondialdehyde (MDA) [15]. Despite being a relatively renowned mechanism and an easier assay technique, other factors such as nutrition and environmental stress can be sources of oxidative stress, which can influence the obtained concentration of MDA. Therefore, the influence of external factors on the MDA concentration should be considered for the application of the biomarker [16].

Acetylcholinesterase (AChE) activity is a neuromuscular biomarker [12]. It is one of the critical enzymes involved in neural functions responsible for maintaining the transmission of nerve impulses by the hydrolysis of the acetylthiocholine neurotransmitter. The regular activity of acetylcholinesterase can be inhibited by the presence of contaminants, such as organophosphates, carbamates [8], pharmaceuticals [6], metals ( $\mathrm{Cd}, \mathrm{Cu}$, and $\mathrm{Pb})$ [17] or surfactants [18]. This inhibition increases the concentration of acetylthiocholine that causes overstimulation of the nervous system, which consequently leads to paralysis and death of the organism in question [19]. Additionally, there may be a variation in the activity of this enzyme due to environmental factors, such as in situ temperature and salinity. It was reported that this parameter is directly correlated to temperature and inversely proportional to salinity [20].

The electron transport system (ETS) activity is a physiological and morphological biomarker [12]. ETS is a complex enzyme system (found in the cell's mitochondrial and microsomal systems) responsible for controlling the utilization of oxygen [21]. The measurement of ETS activity provides information on the potential metabolic activity, which is the theoretically supported maximum respiration rate [21-23]. This method is an indirect approach for the estimation of respiration rates and physical conditions. However, ETS can also be used as an estimate for energy consumption, while the lipid, protein, and carbohydrate contents provide an estimation of the available energy reserves. The exposure to contaminants or other stress factors is documented to have a negative impact on metabolism, which conduces to the depletion of energy reserves and therefore affects the growth [23].

One of the common biological groups used as sentinels for monitoring the water quality and biomarker responses are molluscs. This is attributed to their wide geographic distribution, abundance, and accessibility in the field as well as aquaculture. Bivalves are the most representative ones within the group [24, 25]. The clams within the group are highlighted by their low mobility and filtration feeding habits that allow the determination of localized pollution sources in both water 
and sediments. Furthermore, these molluscs have the potential for bioaccumulation due to their metabolic rates and capacity to filter up to $5 \mathrm{~L} / \mathrm{h}$ of water. Therefore, they are used to detect the contaminants in the environment $[2,26]$. Thus, the three biomarkers mentioned above (LPO, AChE and ETS) were monitored in the Ruditapes decussatus clam species.

Ruditapes decussatus is cultured in the Atlantic coast of France, Spain, Portugal and the Mediterranean basin [10, 27]. In Portugal, it is one of the most important commercial shellfish species of inshore waters, where around $90 \%$ of these clams are harvested in the south coast of Algarve, Ria Formosa coastal lagoon, with a production of 3,261 tons in 2017 [28]. The Ria Formosa lagoon (south coast of Portugal) is a highly productive shallow mesotidal system with high water renewal through six permanent connections to the ocean [29].

Since a majority of the studies on biomarkers were performed in the laboratory under artificially simulated exposure conditions [9, 30], the results may be affected by the unrealistic settings as it is not possible to mimic the real environmental surroundings. Therefore, it is important to perform these studies in the real environment [31, 32].

In order to evaluate the potential impact of the complex mixture of compounds derived from an urban wastewater treatment plant (UWWTP) within the Ria Formosa lagoon under environmental stress conditions in its vicinity, the clams were exposed to realistic conditions in an area influenced by the discharge of effluents. The profile of potential environmental contaminants is a long, expensive and laborious process, which may not reflect the harmful effects on biota. The evaluation of changes in the selected biomarkers at biochemical, cellular and physiological levels is an early and effective control tool for the assessment of the health of aquatic organisms and, ultimately, the ecosystem [33]. Therefore, the clams from the control site (group control of clam from a nursery) were exposed to the potential impact of effluent dispersal from the UWWTP (exposure group located $1.5 \mathrm{~km}$ away from UWWTP) during 1 month in summer. This period is characterized by an increase in the anthropogenic touristic pressure in Ria Formosa with a higher volume of effluents and a high demand of this species. Due to this approach, the response of clams to the environmental conditions was evaluated by the quantification of three biomarkers, namely lipid peroxidation (LPO), acetylcholinesterase (AChE) activity, and electron transport system (ETS) activity.

To complement the information of the biomarkers, the protein and lipid concentrations, condition index and morphometric measurements were also determined for the Ruditapes decussatus clams. Also, the in situ environmental characterization (temperature, salinity, $\mathrm{pH}$ and dissolved oxygen) was performed. The integration of the overall parameters aims to gather information relative to the potential contamination by UWWTP in order to evaluate the need to study the best treatment approach to decrease this problem.

\section{Materials and Methods}

\subsection{Sampling and Exposure Conditions}

Two kilograms of clam samples of Ruditapes decussatus with a "large" size (mean ca. $35 \mathrm{~mm}$ ) were purchased from a local nursery away from direct anthropogenic impact, which was close to the main inlet in Ria Formosa. One kilogram of these clams was used as the control group ( $\mathrm{Cg}$ ). The other kilogram was used as the exposure group (Eg).

The control group was depurated for $24 \mathrm{~h}$ and frozen at $-20^{\circ} \mathrm{C}$ immediately after the purchase. 
The exposure group ( $1 \mathrm{~kg}$ ) was put in cages and exposed to a location ca. $1.5 \mathrm{~km}$ downstream from the Faro Northwest UWWTP to establish the potential impact of the UWWTP effluent discharges away from the zone of the direct impact of those effluents, as reported by Cravo et al. [34]. After one month, the clams from the exposure group were recovered, depurated for $24 \mathrm{~h}$ in the lab and frozen at $-20^{\circ} \mathrm{C}$.

In the exposure site, the temperature, salinity, $\mathrm{pH}$, and dissolved oxygen of water were measured at the beginning and end of the exposure periods using a multiparametric probe YSI 6820.

In the control site (clam nursery), these physicochemical parameters were not directly evaluated as there was no permission for water sampling and water monitorization.

However, the typical physicochemical values in the Ria Formosa lagoon close to the clam nursery were as follows: salinity $\geq 36, \mathrm{pH}$ around 8 and dissolved oxygen close to saturation $[35,36]$.

\subsection{Faro Northwest (NW) UWWTP}

The Faro NW UWWTP located in the South of Portugal (Algarve) is a facility that receives influents from domestic and hospital sources. It has an installed capacity of 44530 population equivalents or $10000 \mathrm{~m}^{3}$ per day. The UWWTP was estimated to discharge $5000 \mathrm{~m}^{3}$ per day into the sensitive Ria Formosa Lagoon region. The plant uses biological treatment with activated sludges and UV disinfection of the effluent in order to comply with the discharge requirements of Ria Formosa Lagoon.

\subsection{Condition Index}

The condition index of the clams was calculated per site, as described by Aafaf et al. [37] using equation 1:

$$
C I(\%)=\frac{\text { wet weight }}{\text { total weight }} \times 100
$$

The total weight (g) was obtained by weighing the whole clam, and wet weight (g) was determined by weighing the soft tissues of the clam (edible part) separately from the shell.

\subsection{Protein Concentration and Lipid Content}

The total protein was determined using five replicates by the Kjeldahl and AOAC methods 928.08 [38]. The results were expressed in g protein/100 g as the wet weight (ww). For the calculation of AChE activity, the protein concentration was evaluated by the Bradford method [39] using bovine serum albumin (BSA) as standard. The protein concentration was expressed in $\mathrm{mg} / \mathrm{ml}$.

The lipid content of the clams was determined by the Soxhlet method (AOAC 960.39) using four replicates. The results were expressed as $\mathrm{g} / 100 \mathrm{~g} w \mathrm{w}$ [38].

\subsection{Biochemical Analysis}

The samples were homogenized using the Ika Ultra-Turrax Tube Drive Control. Due to different sample volume, two centrifuges were used, namely the Sigma 2K15 centrifuge and Hermle Z 100M 
minicentrifuge. The Hitachi U-2000 spectrophotometer was used for the measurement of absorbance.

The following reagents with at least $95 \%$ purity were provided by different suppliers: acetylthiocholine iodide, 5,5'-dithiobis-(2-nitrobenzoic acid) and 2-p-iodo-phenyl 3-p-nitrophenyl 5phenyl tetrazolium chloride (Acros Organics), tris-(hydroxymethyl)aminomethane, Pierce ${ }^{\text {TM }}$ Coomassie (Bradford) Protein Assay Kit (Fisher Scientific), butylated hydroxytoluene (Sigma), 1methyl-2-phenylindole (Alfa Aesar), polyvinylpyrrolidone and Triton X-100 (VWR), malondialdehyde bis(dimethyl acetal) (Merck), and nicotinamide adenine dinucleotide reduced (NADH) and NADPH) (Applichem Panreac).

\subsubsection{ETS}

The ETS activity was determined using the method described by Simcic and Brancelj [22], except that the individually whole clams were considered rather than pools of specimens. Briefly, each soft tissue clam was homogenized in $4 \mathrm{ml}$ of ice-cold homogenization buffer [ $0.1 \mathrm{M}$ phosphate buffer, $\mathrm{pH} 8.4 ; 15 \%(\mathrm{w} / \mathrm{v})$ polyvinylpyrrolidone; $153 \mu \mathrm{M}$ MgSO4; 0.2\% (v/v) Triton X-100] for 2 min at 1000 $\mathrm{rpm}$. This procedure was followed by $20 \mathrm{~s}$ of sonication and centrifugation at $10000 \mathrm{rpm} / 4 \mathrm{~min}$ under $0{ }^{\circ} \mathrm{C}$.

The absorbance of the samples was measured as follows: About $0.05 \mathrm{ml}$ of the supernatant, 1.5 $\mathrm{ml}$ of substrate solution [0.1 $\mathrm{M}$ phosphate buffer, $\mathrm{pH} 8.4 ; 1.7 \mathrm{mM} \mathrm{NADH} ; 0.25 \mathrm{mM}$ NADPH; $0.2 \%$ (V/V) Triton X-100] and $0.5 \mathrm{ml}$ of the coloring solution [2-p-iodo-phenyl 3-p-nitrophenyl 5-phenyl tetrazolium chloride, $8 \mathrm{mM}$ ] were taken for the analysis. The mixture was incubated at $20^{\circ} \mathrm{C}$ for 40 $\mathrm{min}$, and $0.5 \mathrm{ml}$ of the stopping solution [formalin(conc.): $\mathrm{H}_{3} \mathrm{PO}_{4}$ (conc.) = 1:1] was added. The absorbance was then recorded at $490 \mathrm{~nm}$ against the blank sample. The samples were analyzed thrice.

The activity was calculated using equation 2 [40]:

$$
\operatorname{ETS}\left(n m o l \frac{O_{2}}{\min g w w}\right)=\frac{A b s \times V_{H} \times \frac{1}{t} \times V_{A}}{V_{i n c} \times w w \times 31.8} \times 10^{3}
$$

where $A b s$ is the corrected absorbance of the samples, $V_{H}$ is the total homogenate volume $(\mathrm{ml}), \mathrm{t}$ is the incubation time ( $\mathrm{min}), \mathrm{VA}$ is the total assay volume $(\mathrm{ml}), \mathrm{V}_{\text {inc }}$ is the volume of the incubated homogenate, and ww stands for the sample wet weight (g) (Silva et al., 2020). The constant 31.8 is a conversion factor that allows the determination of the equivalent oxygen utilization, assuming that $2 \mu \mathrm{mol}$ of INT-formazan are equivalent to $1 \mu \mathrm{mol}$ of oxygen [41].

\subsubsection{AChE}

The AChE activity was determined by an adapted method on the basis of the procedures described by Ellman et al. [42] and Porte et al. [43]. The hydrolyzation of acetylthiocholine led to the formation of thiocholine that, in turn, reacted with 5,5-dithiobis-2-nitrobenzoate ion (DTNB), forming a yellow-colored anion 5-thio-2-nitrobenzoic acid. The principle of this method is based on the monitoring of the formation rate of this anion [42].

The whole soft tissues of the clams were individually homogenized in a mixture of Tris- $\mathrm{HCl}(100$ $\mathrm{mM}, \mathrm{pH}$ 8) buffer at a ratio of 1:5 [sample $(\mathrm{g})$ :buffer $(\mathrm{ml})$ ] and $10 \%$ Triton X-100 at a ratio of 1:10 
[buffer $(\mathrm{ml})$ :Triton $(\mu \mathrm{l})$ ]. The homogenization was performed for $2 \mathrm{~min}$ at $1000 \mathrm{rpm}$. The samples were then centrifuged for $30 \mathrm{~min}$ at $15000 \mathrm{rpm}$ under $4^{\circ} \mathrm{C}$. The supernatant was divided in half, where one of the aliquots stored at $-60^{\circ} \mathrm{C}$ to later be used to determine the protein content of the samples, and the other was used to determine the AChE activity immediately after homogenization.

For the determination of activity, the absorbance of the three blanks and two duplicate were registered for each sample at $405 \mathrm{~nm}$ against a blank sample of Tris- $\mathrm{HCl}$ buffer. In order to determine the activity of the blank sample, $1.6 \mathrm{ml}$ of the buffer and $200 \mu \mathrm{L}$ of DTNB ( $1 \mathrm{mM}$ ) were stabilized at room temperature for $5 \mathrm{~min}$. This was followed by the addition of $200 \mu \mathrm{L}$ of $\mathrm{AChl}(10 \mathrm{mM})$, and the absorbances were measured at $405 \mathrm{~nm}$ for $60 \mathrm{~s}$. A similar procedure was used to determine the activity of the samples, except that $1.5 \mathrm{ml}$ of the buffer, $200 \mu \mathrm{L}$ of DTNB and $100 \mu \mathrm{L}$ of the sample were incubated.

The initial ( $0 \mathrm{~s})$ and final $(60 \mathrm{~s})$ absorbances of both the samples and blanks were registered, and $\Delta \mathrm{A}\left(\mathrm{min}^{-1}\right)$ was calculated.

The AChE activity was calculated using equation 3 [40]:

$$
A C h E\left(\frac{n m o l}{\min } m g \text { prot }\right)=\frac{\Delta A}{\varepsilon} \times \frac{V_{C}}{V_{S}} \times \frac{10^{3}}{[P]} \times 10^{6}
$$

where, $\Delta A\left(\mathrm{~min}^{-1}\right)$ is the difference between the initial and final absorbances, $\varepsilon$ is the extinction coefficient $\left(1.36 \times 10^{4} \mathrm{ml} / \mathrm{nmol}\right), V_{C}$ is the cuvette volume $(\mathrm{ml}), V_{S}$ is the sample volume $(\mu \mathrm{l})$, and $[P]$ is the total protein concentration $(\mathrm{mg} / \mathrm{ml})$.

\subsubsection{LPO}

The methods described by Gerard-Monnier et al. [44] and OxisResearchTM [45] for LPO determination were modified in this study.

For the LPO method, the whole soft tissues of the clams were individually homogenized in a mixture of tris- $\mathrm{HCl}(0.02 \mathrm{M}$ ) buffer at a ratio of 3:1 [buffer $(\mathrm{ml})$ : sample $(\mathrm{g})$ ] (with a minimum of $5 \mathrm{ml}$ per sample) and BHT $(0.5 \mathrm{M})$ at a ratio of 1:10 [buffer $(\mathrm{mL})$ : BHT $(\mu \mathrm{l})]$. The homogenization of the sample was performed at $1000 \mathrm{rpm}$ for $2 \mathrm{~min}$. The samples were then centrifuged for $45 \mathrm{~min}$ at $15000 \mathrm{rpm}$ under $4{ }^{\circ} \mathrm{C}$. Unlike the two previous biomarkers, the absorbance of the samples was determined, given that the supernatants were stored stably at $-80^{\circ} \mathrm{C}$.

A calibration curve with the following concentrations was prepared and read once before any samples: eight MDA levels between $0 \mu \mathrm{M}$ (blank) and $20 \mu \mathrm{M}$ was prepared by the dilution of several volumes $(0,50,125,250,500,1000,1500$ and $2000 \mu \mathrm{L})$ of a standard solution of MDA at $20 \mu \mathrm{M}$ $\mathrm{mg} / \mathrm{L}$ to $2 \mathrm{ml}$ using Tris-NaCl.

After this procedure, $300 \mu \mathrm{L}$ of each MDA standard was pipetted and transferred to an Eppendorf tube (in triplicate) followed by the addition of $975 \mu$ l of diluted R1 (18 ml of stock N-methyl-2phenylindole solution prepared in acetonitrile and $6 \mathrm{~mL}$ of methanol) and $225 \mu \mathrm{l}$ of methanesulfonic acid $(15.4 \mathrm{M})$, which were mixed thoroughly. The Eppendorf tubes were incubated under $45^{\circ} \mathrm{C}$ for $60 \mathrm{~min}$. Thereafter, the absorbance values were recorded in $2 \mathrm{ml}$ of cuvettes at $586 \mathrm{~nm}$ against a Tris- $\mathrm{NaCl}$ ( $\mathrm{pH}$ 8.6) blank sample, and a calibration curve of the absorbance versus concentration was plotted.

The analysis of the experimental samples was performed using the same procedure with the exception that $300 \mu$ l of previously prepared supernatant was pipetted to the Eppendorf tubes (in 
duplicate). After the incubation period, the samples were centrifuged at $6000 \mathrm{rpm}$ for $1 \mathrm{~min}$ due to the formation of precipitates.

The surrogate for LPO determination, namely MDA concentration, was calculated using equation 4:

$$
\operatorname{MDA}\left(\text { nmol } \frac{M D A}{g} \text { protein }\right)=\frac{\frac{A b s-b}{a} \times V_{T}}{w w \times[P]} \times 10^{3}
$$

where, Abs is the recorded absorbance of the samples, the terms $a$ and $b$ are obtained from the linear equation corresponding to the calibration curve $(y=a x+b) ; V_{T}$ is the volume of Tris- $\mathrm{HCl}$ used to homogenize the sample $(\mathrm{ml}), \mathrm{ww}$ is the wet weight of the sample $(\mathrm{g})$, and $[\mathrm{P}]$ is the protein concentration (mg/g).

\subsection{Statistical Analysis}

All the presented results are expressed as mean value \pm standard deviation (SD).

The results obtained from the clam samples (control and exposure groups) and biomarkers were analyzed to detect the possible statistical differences using the Kruskal-Wallis test and one-way ANOVA (analysis of variance). Both the tests were evaluated to show a significance level of $5 \%$ ( $\alpha=$ $0.05)$.

The principal component analysis (PCA), an unsupervised multivariate analytical method, was built using MetaboAnalyst 4.0 [46-49] to discriminate the main variables responsible for the variance of biomarkers, morphometric and nutritional factors. The variables considered for the analysis were ETS, AChE and LPO biomarkers, proteins, lipids, and condition index (CI). All the variables were presented as their mean values.

\section{Results and Discussion}

\subsection{Environmental Characterization Context}

The in situ water characteristics were measured at the beginning and end of the exposure experiments, as shown in Table 1.

Table 1 Temperature, salinity, $\mathrm{pH}$, and dissolved oxygen (\%) at the exposure site in the beginning and at the end of the exposure period of the clams.

\begin{tabular}{llllllll}
\hline $\boldsymbol{T}\left({ }^{\circ} \mathbf{C}\right)$ & \multicolumn{3}{c}{ Salinity } & $\mathbf{p H}$ & & \multicolumn{2}{c}{ Dissolved Oxygen $\mathbf{~ m g} / \mathbf{L} ; \%$ saturation) } \\
\hline June & July & June & July & June & July & June & July \\
22 & 28 & 36.8 & 37.1 & 7.7 & 8.1 & $5.6 ; 79$ & $8.3 ; 140$ \\
\hline
\end{tabular}

All the parameters taken for the study showed higher values at the end of the exposure period. Globally, the water temperature followed the typical seasonal pattern of atmospheric temperature, with higher values in July that mostly exceeded $25^{\circ} \mathrm{C}$. 
The water salinity of both the samplings showed the typical values corresponding to that of marine waters. Therefore, the exposure site showed no direct influence from the effluents/freshwater $(S>36)$ [50].

The $\mathrm{pH}$ values were in the range of 7.7 to 8.1. This was also similar to the $\mathrm{pH}$ values found in marine waters [51].

The percentage of dissolved oxygen varied with months. The hour of the sampling showed a significant impact on the resultant values. The minimum value $(79 \%)$ was achieved at the exposure site in the early morning of June 2016, while the maximum (140\%) was recorded in the period from noon to $2 \mathrm{pm}$.

\subsection{Morphometric Characteristics, Condition Index and Concentration of Proteins and Lipids}

Table 2 shows the morphometric characteristics of the clams. Significant correlations were observed between the length and total mass of the clams: $r=0.89(p<0.01)$ for the control group and $r=0.88(p<0.01)$ for exposure group.

The $\mathrm{Cl}$ was lower in the clams of the exposure group. This index reflects the physiological status of the organisms. It showed that the exposed bivalves might be under more stress after a month than those observed in the control site, where they live in natural environmental conditions, as reported by other authors [12]. The clams from the exposure group showed a lower value of $\mathrm{Cl}$, edible mass and percentage of lipids (Table 2) compared to those from the control group, which indicated a decrease in body weight and lipid content in the former after a month. This may suggest the emission of gametes, as reflected by the loss of lipid content. The variation of $\mathrm{Cl}$ may be associated with fluctuations in the reproductive cycle of the clams. Generally, the spawning of the species occurs during the summer [52]. Although the values of $\mathrm{Cl}$, edible mass and lipids were lower in the clams from the exposure group, the differences were not significant $(p>0.05)$.

\subsection{Biomarker Response}

The use of several biomarkers is the best approach to achieve an integrated overview of the biological responses to the mixtures of contaminants even under low concentrations [53].

There is an allometric dependency of the rate of energy metabolism on the body weight of the bivalves [54]. This change in energy metabolism during the growth of the animals is strongly influenced by the habitat conditions, mainly environmental factors such as temperature, salinity and dissolved oxygen, as well as bioavailability of the contaminants [12, 30, 54].

Table 2 Summary of the length, width, thickness, total mass, shell mass, edible mass, condition index $(n=30)$, and percentage of total lipids and proteins $(n=5)$ in Ruditapes decussatus from the control and exposure groups.

\begin{tabular}{lll}
\hline Clams' parameters & Control group & Exposure group \\
\hline Total mass $(\mathrm{g})$ & $6.7 \pm 2.33$ & $6.8 \pm 1.78$ \\
Edible mass $(\mathrm{g})$ & $2.7 \pm 0.93$ & $2.4 \pm 0.63$ \\
Shell mass $(\mathrm{g})$ & $3.9 \pm 1.38$ & $4.2 \pm 1.11$ \\
$\mathrm{Cl}(\%)$ & $39.3 \pm 2.25$ & $34.5 \pm 3.43$ \\
Length $(\mathrm{mm})$ & $33.0 \pm 3.27$ & $33.7 \pm 3.05$ \\
\hline
\end{tabular}




\begin{tabular}{lll}
\hline Width $(\mathrm{mm})$ & $23.7 \pm 2.52$ & $24.3 \pm 2.28$ \\
Thickness $(\mathrm{mm})$ & $13.1 \pm 5.57$ & $15.6 \pm 1.55$ \\
Total lipids $(\%)$ & $3.07 \pm 2.15$ & $1.06 \pm 0.07$ \\
Total protein $(\%)$ & $9.61 \pm 0.008$ & $10.09 \pm 0.002$ \\
\hline
\end{tabular}

The impact of these conditions (environmental and/or chemical stresses) upon bivalves can be evaluated by the quantification of the target biomarkers, such as electron transport system (ETS), acetylcholinesterase (AChE) and lipid peroxidation (LPO) as determined in the present study.

Table 3 shows the profile of the three selected biomarkers (ETS, AChE and LPO) in Ruditapes decussatus clams exposed to potential contamination from the effluent of the UWWTP in Ria Formosa located at a distance of $1.5 \mathrm{~km}$ away from the exposure site. The results were obtained after one month of exposure.

Among the three biomarkers, there were significant statistical differences $(p<0.05)$ in the LPO results obtained from the two sites (control and exposure sites). The spatial statistical differences might suggest that the site of exposure does produce a noticeable variation corresponding to the biomarker response, where a particular type of stress is responsible for the spatial fluctuation. This may be attributed to the fluctuations in the environmental factors (such as water temperature, salinity, dissolved oxygen) or the presence of some target contaminants $[12,55,56]$.

Table 3 Electron transport system (ETS), acetylcholinesterase (AChE) and lipid peroxidation (LPO) contents in the Ruditapes decussatus clams from the control and exposure group. The statistical tests used were ANOVA and Kruskal-Wallis $(n=30)$.

\begin{tabular}{lll}
\hline Biomarker & Control group & Exposure group \\
\hline ETS (nmol O $/$ min g ww) & $27.2 \pm 0.73$ & $30.2 \pm 1.80$ \\
AChE (nmol/min mg prot & $4.0 \pm 0.47$ & $4.6 \pm 0.96$ \\
LPO (nmol MDA/g prot) & $248.9 \pm 14.78^{\mathrm{a}, \mathrm{b}}$ & $101.5 \pm 15.15^{\mathrm{a}, \mathrm{b}}$ \\
\hline
\end{tabular}

a significant statistical for the same biomarker by the ANOVA test

${ }^{b}$ significant statistical for the same biomarker by the Kruskal-Wallis test

Significant statistical differences between the control and exposure groups $(p<0.05)$ were only observed in the LPO results evaluated by the ANOVA and Kruskal-Wallis tests relative to the AChE and ETS analysis (mean: 4.0 and $4.6 \mathrm{nmol} / \mathrm{min} \mathrm{mg}$ protein and 27.2 and $30.2 \mathrm{nmol} \mathrm{O}_{2} / \mathrm{min} \mathrm{g} \mathrm{ww}$, respectively; $p>0.05$ ).

The ETS assay is a useful metabolic indicator illustrating an allometric relationship of a typical metabolic function with body size. However, it is not a simple conservative measure of body mass. The variation in the dry weight and organic $\mathrm{N}$ are also important factors. Nevertheless, the mass of organic $\mathrm{N}$ is a better parameter for scaling the ETS activity, as it is closely related to organic matter and hence, to metabolically active tissues than the total dry weight [57]. Other studies also demonstrated that oxygen consumption is closely dependent on the size of the organism [58].

The ETS activity is closely related to the salinity of the bivalves. The specimens from the sites with higher salinity showed lower ETS activity. This correlation observed for mussels may also be applicable to clams [56]. The combined effect of increased salinity may be responsible for the lower and similar activity values recorded for both groups $(p>0.05)$. This might provide evidence for the 
significance of environmental factors as sources of stress that influence the clams, as explained by the relevant changes in the water temperature and dissolved oxygen.

Other studies conducted on bivalves confirmed the positive correlation between ETS activity and growth in clams [59].

The increased metabolic activity is expressed by the ETS levels, representing an attempt to fight against the oxidative stress upon the expenditure of their energy storage to prevent LPO for metabolic defenses involved in the detoxification processes $[9,60]$. Although clams were able to increase their metabolic activity, the defense mechanisms might not be sufficiently efficient to fight against LPO [9] as it will be shown afterwards.

The AChE activity (Table 3 ) presents some variations between the groups. The clams in the control group were presumably from a site with low contamination, and those in the exposure group were far from the zone of influence of the UWWTP $(\approx 1.5 \mathrm{~km})$.

From Table 1, it was observed that the amount of dissolved oxygen can cause stress due to the saturation of $140 \%$ attained during the day, suggesting a decrease in the values recorded at night. The variation of in situ temperature, salinity, and dissolved oxygen caused fluctuations in the AChE activity. The AChE activity correlated negatively with the salinity and dissolved oxygen in different bivalve species $[20,61]$, while it was directly proportional to the temperature $[20,61,62]$. These results noticeably demonstrated the need to consider the potential influence of abiotic factors such as temperature and salinity on AChE activity upon the application of this biomarker to monitor the exposure in places with salinity gradients. The water temperatures of the studied exposure sites (Table 1) were similar, ranging from $25^{\circ} \mathrm{C}$ to $27^{\circ} \mathrm{C}$ between June and July. The highest variation in salinity was observed between the first day of exposure and the time of recovery of the clams. The AChE activity values (Table 3 ) were integrative and representative measurements recorded upon one month of exposure against the water characteristics (Table 1) that represented only a snapshot of the environmental conditions, which was highly variable in time and space.

Furthermore, the obtained AChE activity levels in the same species from a study conducted in the Ria Formosa during 2007 and 2008 were compared [63]. The studies showed similar yet higher values. This suggested a lower impact on the activity of the present samples relative to that reported in 2007-2008. For example, the highest activity registered during the same months (June and July) was $2.6 \mathrm{nmol} / \mathrm{min} \mathrm{mg}$ protein which was lower than that obtained in the present study upon consideration of the two groups. The saturation of dissolved oxygen, $\mathrm{pH}$ and accumulation of organic matter on the sediments could also influence the biomarker and alter its response to some extent. This discrepancy may be responsible for the lower activity levels reported during the study conducted in 2007-2008.

There were significant differences in the LPO values between the control and exposure groups. The LPO values were surprisingly higher in clams from the control group ( $248.9 \mathrm{nmol}$ MDA/g protein) than those from the exposure group (101.5 nmol MDA/g protein).

The higher LPO concentration registered in the control group may likely be attributed to some form of stress other than the contaminants, as stated for AChE activity, such as environmental conditions (ex: nutritional factors or dissolved oxygen) or biotic sensitivity before the spawning process that might negatively influence the MDA concentrations. This phenomenon was reported in a previous study considering the same species of clams from Ria Formosa [63]. This reinforces the statement by Vidal et al. [64] on the consideration of the effects of abiotic factors for the 
environmental studies using biomarkers. However, the nutritional factors were irrelevant for these specimens, as indicated by the LPO data in Table 3.

The comparison of the LPO data obtained in this study with those conducted in 2007-2008 [63], showed an increase in the MDA concentrations for the former. For example, the highest MDA concentration was registered in July 2008 (204.3 nmol MDA/g protein), which was equivalent to that obtained for clams in the control group before the spawning period.

Thus, a very important aspect of the multi-biomarker approach is the detailed knowledge of the basal biomarker response and its seasonal variation to distinguish the pollution-induced effects from those induced by the natural biological cycle of the clams, including the reproductive cycle and spawning period $[65,66]$.

There are limited studies on the multi-biomarker univariate approach without an integrated overview that allows the global assessment of the influence of contaminants and environmental conditions at each site of exposure, allowing the overview of biomarker responses and corresponding processes. Therefore, a principal component analysis (PCA) model was built to integrate the data (Figure 1). To perform the PCA analysis, the biomarkers, morphometric characteristics and nutritional parameters were considered. Since there were only two studied sites (control vs. exposure groups), only one principal component (PC1) was calculated, explaining $100 \%$ of the variance of the data, enabling the spatial separation of the variables (biomarkers, morphological and nutritional parameters) by their relevance on the separation between the two exposure sites. The PC1 showed a separation between the exposed (positive PC1) and control sites (negative PC1), as shown in Figure $1 \mathrm{~A}$.

From the corresponding loadings 1 plot (Figure 1B), the variable LPO was identified as the most relevant factor for the separation of the two sites, which was elevated in the control group. The LPO variable was relevant to the observed separation (Figure 1B). In fact, the PCA model highlights the association of higher amounts of LPO with high condition index $(\mathrm{CI})$ and lipids among the clams from the control site. In contrast, the clams from the exposure site showed slightly higher protein content, AChE activity and ETS biomarker activity (Figure 1B). 
a)

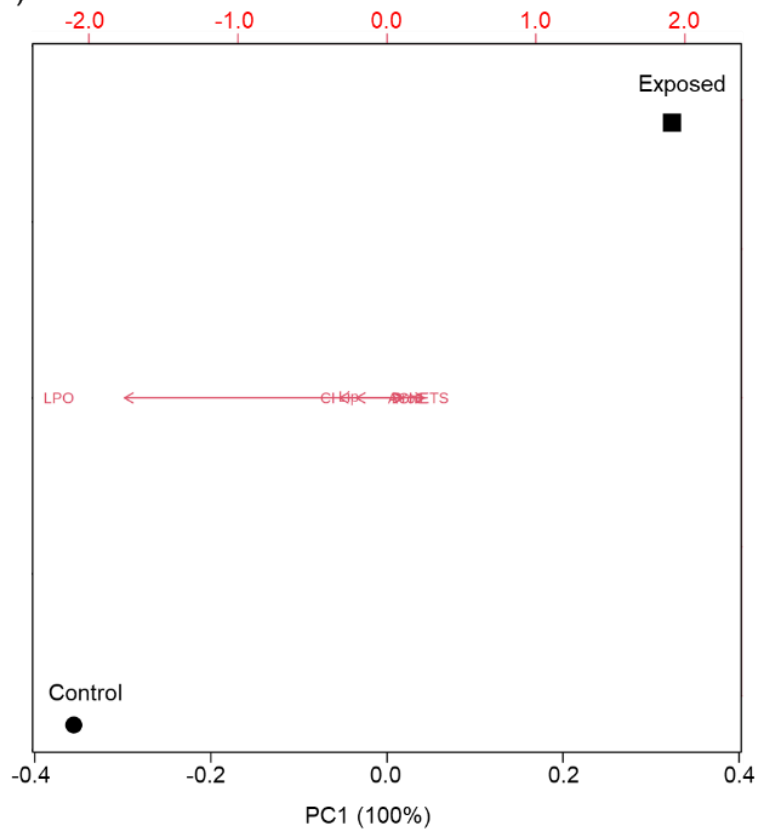

b)

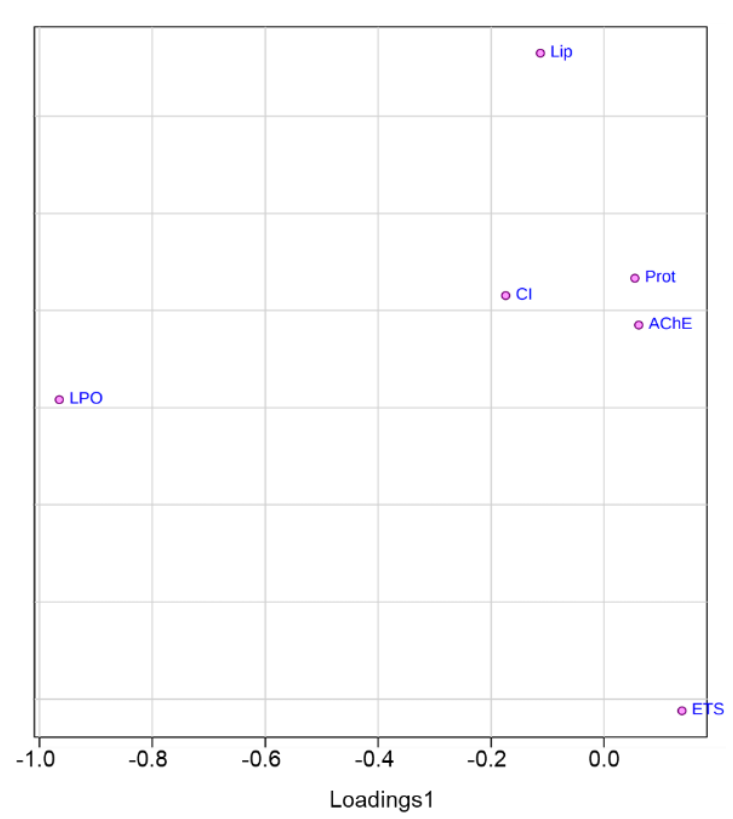

Figure 1 Principal component analysis (PCA) of the nutritional and biochemical parameters used to evaluate the condition of the Ruditapes decussatus clam. The considered parameters were the electron transport system (ETS), lipid peroxidation (LPO), and acetylcholinesterase (AChE), morphometric characteristics such as condition index $(\mathrm{Cl})$, nutritional factors such as lipids (Lip) and proteins content (Prot). (A) bi-plot with the scores (separation between the groups) and loadings1 (in red, projection of the influence of each variable on the separation) representation; (B) loadings1 plot.

From this data, the clams from the control site were mostly influenced by the high levels of the damage biomarker LPO. This confirms the difficulty of establishing the baseline levels of the biomarkers in less contaminated regions due to the range of natural variability. However, the maximum LPO recorded for the clams in the control group can be attributed to their higher sensitivity before the spawning period than those observed after one month of exposure. Consequently, the alterations in the environmental (Table 1) or physiological parameters (Table 2) can have a relevant effect on the biomarker responses, as reported by other authors $[62,67]$. The variability of the biomarkers may also depend on the variation of environmental parameters (e.g., high seawater temperature, changes in salinity, intense solar irradiance, oxygen decrease, etc.) that could induce higher physiological stress, as already observed in other bivalve species $[62,65,66]$. This data confirmed that the temporal and spatial clams at those locations in the Ria Formosa lagoon were differently impacted by the contaminants, environmental and/or physiological factors, which distinctively influenced the biomarker responses.

In summary, the PCA of the overall data (Figure 1) revealed that the biomarker responses changed spatially with the variation in the environmental conditions. During the summer season, high water temperatures exceeding $25^{\circ} \mathrm{C}$ (high solar radiance) and the potential increase in organic matter within the sediment may lead to a decrease in the oxygen level, $\mathrm{pH}$ of the water and interstitial water in the sediments particularly during the night that may also affect the biomarker responses and undermine the health of the clams. 


\section{Conclusions}

Different biomarker responses were observed during this study. The influence of environmental factors or other stressors were studied. The LPO is a damage biomarker, which appears as a secondary factor for the interpretation of the data. The LPO value was maximum in clams from the control group due to their high sensitivity toward the detoxification of compounds (organic and inorganic) or environmental stress before the spawning period. Moreover, the loss of body mass and increased environmental pressure during summer may confound the response of the biomarker. This study can be considered as an adequate starting point toward the study. In order to draw definitive conclusions, a more target-specific approach regarding the site characterization, such as an analysis of the prevalent contaminants responsible for the lipid peroxidation results coupled with a broader battery of the biomarker analysis, may be required.

Considering the complex mixtures of the present contaminants, the biomarker responses provided valuable information for environmental assessment. Nevertheless, it is important to identify the interactions (synergistic, addition or antagonistic effects), including the environmental and biological factors induced by the natural biological cycle of clams, including the reproductive cycle and spawning period that might complicate the general interpretation of the biomarker response. Abiotic factors can confound the biomarker response and find significance in a multibiomarker approach.

\section{Author contributions}

Conceptualization, A.C. and C.M.M.A; Methodology, A.C., C.M.M.A. and S.S.; Sampling, A.C. and C.C; Formal Analysis, S.S.; Writing-Original Draft Preparation, S.S.; Writing-Review \& Editing, C.M.M.A, J.R. and A.C.; Statistical Analysis, J.R.

\section{Competing Interests}

Authors declare no conflict of interest.

\section{References}

1. Hanson N, Halling M, Norin H. Biomarkers for environmental monitoring - Suggestions for Norwegian monitoring programmes [Internet]. Trondheim, Norway: Miljødirektoratet; 2013. Available from: https://www.semanticscholar.org/paper/Biomarkers-for-EnvironmentalMonitoring-Suggestions-Hanson/6901c1154f942faf263df9bea41b07dfa9bd86c0.

2. National Research Council (US) Committee on Animals as Monitors of Environmental Hazards. 2. Concepts and definitions: Characteristics of animal sentinel systems. In: Animals as monitors of environmental hazards. Washington, DC: The National Academies Press; 1991.

3. Bossart GD. Marine mammals as sentinel species for oceans and human health. Vet Pathol. 2011; 48: 676-690.

4. United Nations Environment Programme, World Health Organization, International Labour Organisation. Biomarkers and risk assessment: Concepts and principles - environmental health criteria 155. Geneva: World Health Organization; 1993.

5. Kerambrun E, Sanchez W, Henry F, Amara R. Are biochemical biomarker responses related to 
physiological performance of juvenile sea bass (Dicentrarchus labrax) and turbot (Scophthalmus maximus) caged in a polluted harbour? Comp Biochem Physiol C-Toxicol Pharmacol. 2011; 154: 187-195.

6. Li ZH, Lu GH, Yang XF, Wang C. Single and combined effects of selected pharmaceuticals at sublethal concentrations on multiple biomarkers in Carassius auratus. Ecotoxicology. 2012; 21: 353-361.

7. Hook SE, Gallagher EP, Batley GE. The role of biomarkers in the assessment of aquatic ecosystem health. Integr Environ Assess Manag. 2014; 10: 327-341.

8. van der Oost R, Beyer J, Vermeulen NP. Fish bioaccumulation and biomarkers in environmental risk assessment: A review. Environ Toxicol Pharmacol. 2003; 13: 57-149.

9. Cruz D, Almeida A, Calisto V, Esteves VI, Schneider RJ, Wrona FJ, et al. Caffeine impacts in the clam Ruditapes philippinarum: Alterations on energy reserves, metabolic activity and oxidative stress biomarkers. Chemosphere. 2016; 160: 95-103.

10. Bebianno MJ, Géret F, Hoarau P, Serafim MA, Coelho MR, Gnassia-Barelli M, et al. Biomarkers in Ruditapes decussatus: A potential bioindicator species. Biomarkers. 2004; 9: 305-330.

11. Sarkar A, Ray D, Shrivastava AN, Sarker S. Molecular biomarkers: Their significance and application in marine pollution monitoring. Ecotoxicology. 2006; 15: 333-340.

12. Farris JL, Van Hassel JH. Freshwater bivalve ecotoxicology. Boca Raton, FL: CRC Press; 2007.

13. Livingstone DR. Oxidative stress in aquatic organisms in relation to pollution and aquaculture. Revue Med Vet. 2003; 154: 427-430.

14. de Almeida EA, Bainy AC, Loureiro AP, Martinez GR, Miyamoto S, Onuki J, et al. Oxidative stress in Perna perna and other bivalves as indicators of environmental stress in the Brazilian marine environment: Antioxidants, lipid peroxidation and DNA damage. Comp Biochem Physiol A Mol Integr Physiol. 2007; 146: 588-600.

15. Srain B, Rudolph A. Acetylcholinesterase activity, antioxidant defenses, and lipid peroxidation in the clam Semele solida: Can this species be used as a bioindicator? Rev Biol Mar Oceanogr. 2010; 45: 227-233.

16. Romeo M, Gnassia-Barelli M. Effect of heavy metals on lipid peroxidation in the Mediterranean clam Ruditapes decussatus. Comp Biochem Physiol C Pharmacol Toxicol Endocrinol. 1997; 118: 33-37.

17. Lionetto MG, Caricato R, Giordano ME, Pascariello MF, Marinosci L, Schettino T. Integrated use of biomarkers (acetylcholinesterase and antioxidant enzymes activities) in Mytilus galloprovincialis and Mullus barbatus in an Italian coastal marine area. Mar Pollut Bull. 2003; 46: 324-330.

18. Regoli F, Principato G. Glutathione, glutathione-dependent and antioxidant enzymes in mussel, Mytilus galloprovincialis, exposed to metals under field and laboratory conditions: Implications for the use of biochemical biomarkers. Aquat Toxicol. 1995; 31: 143-164.

19. Bocquené G, Galgani F. Biological effects of contaminants: Cholinesterase inhibition by organophosphate and carbamate compounds. Copenhagen, Denmark: International Council for the Exploration of the Sea (ICES); 1998.

20. Pfeifer S, Schiedek D, Dippner JW. Effect of temperature and salinity on acetylcholinesterase activity, a common pollution biomarker, in Mytilus sp from the south-western Baltic Sea. J Exp Mar Bio Ecol. 2005; 320: 93-103.

21. Packard TT. The measurement of respiratory electron transport activity in marine 
phytoplankton. J Mar Res. 1971; 29: 235-244.

22. Simcic T, Brancelj A. Respiratory electron transport system (ETS) activity as an estimator of the thermal tolerance of two Daphnia hybrids. J Plankton Res. 2004; 26: 525-534.

23. De Coen WM, Janssen CR. The use of biomarkers in Daphnia magna toxicity testing. IV. Cellular Energy Allocation: A new methodology to assess the energy budget of toxicant-stressed Daphnia populations. J Aquat Ecosyst Stress Recover. 1997; 6: 43-55.

24. De Lafontaine $Y$, Gagné F, Blaise C, Costan G, Gagnon P, Chan HM. Biomarkers in zebra mussels (Dreissena polymorpha) for the assessment and monitoring of water quality of the St Lawrence River (Canada). Aquat Toxicol. 2000; 50: 51-71.

25. Farrington JW. Bivalves as sentinels of coastal chemical pollution: The mussel (and oyster) watch. Oceanus. 1983; 26: 18-29.

26. Kremer JN, Nixon SW. A coastal marine ecosystem: Simulation and analysis. Berlin Heidelberg Germany: Springer; 1978.

27. FAO yearbook: Fishery and aquaculture statistics [Internet]. Food and Agriculture Oraganization of the United Nations; 2012. Available from: https://rowman.com/ISBN/9789250082936/FAOYearbook-Fishery-And-Aquaculture-Statistics-2012.

28. Direção-geral de recursos naturais, segurança e serviços marítimos. Aquicultura e salicultura. In: Estatísticas da pesca - 2017. Lisbon, Portugal: Instituto Nacional de Estatística; 2018.

29. Cravo A, Cardeira S, Pereira C, Rosa M, Madureira M, Rita F, et al. Nutrients and particulate matter exchanges through the Ria Formosa coastal lagoon, Portugal. J Coast Res. 2013; 2: 19992004.

30. Coppola F, Almeida A, Henriques B, Soares A, Figueira E, Pereira E, et al. Biochemical responses and accumulation patterns of Mytilus galloprovincialis exposed to thermal stress and Arsenic contamination. Ecotoxicol Environ Saf. 2018; 147: 954-962.

31. Chiesa S, Chainho P, Almeida Â, Figueira E, Soares AM, Freitas R. Metals and As content in sediments and Manila clam Ruditapes philippinarum in the Tagus estuary (Portugal): Impacts and risk for human consumption. Mar Pollut Bull. 2018; 126: 281-292.

32. Velez C, Freitas R, Soares A, Figueira E. Bioaccumulation patterns, element partitioning and biochemical performance of Venerupis corrugata from a low contaminated system. Environ Toxicol. 2016; 31: 569-583.

33. Cajaraville MP, Bebianno MJ, Blasco J, Porte C, Sarasquete C, Viarengo A. The use of biomarkers to assess the impact of pollution in coastal environments of the Iberian Peninsula: A practical approach. Sci Total Environ. 2000; 247: 295-311.

34. Cravo A, Fernandes D, Damião T, Pereira C, Reis MP. Determining the footprint of sewage discharges in a coastal lagoon in South-Western Europe. Mar Pollut Bull. 2015; 96: 197-209.

35. Cravo A, Cardeira S, Pereira C, Rosa M, Alcântara P, Madureira $M$, et al. Nutrients and chlorophyll-a exchanges through an inlet of the Ria Formosa Lagoon, SW Iberia during the productive season - unravelling the role of the driving forces. J Sea Res. 2019; 144: 133-141.

36. Rosa A, Cardeira S, Pereira C, Rosa M, Madureira M, Rita F, et al. Temporal variability of the mass exchanges between the main inlet of Ria Formosa lagoon (southwestern Iberia) and the Atlantic Ocean. Estuar Coast Shelf Sci. 2019; 228: 106349.

37. Aafaf $\mathrm{E}$, Abdelfettah M, Abdesslam F, Redouane M, Abdelali B. Adaptation of bivalve molluscs to environmental conditions in the coastal region of El jadida (Morocco): Case of mytilus galloprovincialis. Eur Sci J. 2017; 13: 226-241. 
38. AOAC International. Official Methods of Analysis of AOAC INternational. 17th ed. Gaithersburg, Maryland, USA: AOAC International; 2000. A second revision of this edition. Gaithersburg, Maryland, USA: AOAC International; 2003). 16th edition. Arlington, Virginia, USA: A. Assoc Off Anal Chem Int; 1995. 15th edition. Arlington, Virginia, USA: A. Assoc Off Anal Chem Int; 1990.

39. Bradford MM. A rapid and sensitive method for the quantitation of microgram quantities of protein utilizing the principle of protein-dye binding. Anal Biochem. 1976; 7: 248-254.

40. Silva S, Cravo A, Ferreira C, Correia C, Almeida CM. Biomarker responses of the clams ruditapes decussatus exposed to a complex mixture of environmental stressors under the influence of an urban wastewater treatment plant. Environ Toxicol Chem. 2021; 40: 272-283.

41. Kenner RA, Ahmed SI. Measurements of electron-transport activities in marine phytoplankton. Mar Biol. 1975; 33: 119-127.

42. Ellman GL, Courtney KD, Andres V, Featherstone RM. A new and rapid colorimetric determination of acetylcholinesterase activity. Biochem Pharmacol. 1961; 7: 88-95.

43. Porte C, Escartin E, Borghi V. Chapter 10 - Biochemical tools for the assessment of pesticide exposure in a deltaic environment: The use of cholinesterases and carboxylesterases. In: Biomarkers in marine organisms: A practical approach. Amsterdam, Netherlands: Elsevier; 2001.

44. Gerard-Monnier D, Erdelmeier I, Regnard K, Moze-Henry N, Yadan JC, Chaudiere J. Reactions of 1-methyl-2-phenylindole with malondialdehyde and 4-hydroxyalkenals. Analytical applications to a colorimetric assay of lipid peroxidation. Chem Res Toxicol. 1998; 11: 1176-1183.

45. OxisResearch ${ }^{\mathrm{TM}}$. Colorimetric assay for lipid peroxidation, BIOXYTECH LPO-586, OXIS Health Products. Portland: OXIS International, Inc; [cited date 2021 June 8]. Available from: http://www.percipiobio.com/pub/PDF/inserts/77460604.pdf.

46. Chong J, Wishart DS, Xia JG. Using MetaboAnalyst 4.0 for comprehensive and integrative metabolomics data analysis. Curr Protoc Bioinforma. 2019; 68: e86.

47. Xia JG, Sinelnikov IV, Han B, Wishart DS. MetaboAnalyst 3.0-making metabolomics more meaningful. Nucleic Acids Res. 2015; 43: W251-W257.

48. Xia JG, Mandal R, Sinelnikov IV, Broadhurst D, Wishart DS. MetaboAnalyst 2.0-a comprehensive server for metabolomic data analysis. Nucleic Acids Res. 2012; 40: W127-W133.

49. Xia JG, Psychogios N, Young N, Wishart DS. MetaboAnalyst: A web server for metabolomic data analysis and interpretation. Nucleic Acids Res. 2009; 37: W652-W660.

50. Brown WS. Physical properties of seawater. In: Springer handbook of ocean engineering. New York: Springer, Cham; 2016.

51. Marion GM, Millero FJ, Camões MF, Spitzer P, Feistel R, Chen CT. PH of seawater. Mar Chem. 2011; 126: 89-96.

52. Matias D, Joaquim S, Matias AM, Moura P, de Sousa JT, Sobral P, et al. The reproductive cycle of the European clam Ruditapes decussatus (L., 1758) in two Portuguese populations: Implications for management and aquaculture programs. Aquaculture. 2013; 406-407: 52-61.

53. Monserrat JM, Martínez PE, Geracitano LA, Amado LL, Martinez CM, Pinho GL, et al. Pollution biomarkers in estuarine animals: Critical review and new perspectives. Comp Biochem Physiol C Toxicol Pharmacol. 2007; 146: 221-234.

54. Vladimirova IG, Kleimenov SY, Radzinskaya LI. The relation of energy metabolism and body weight in bivalves (Mollusca: Bivalvia). Biol Bull. 2003; 30: 392-399.

55. Coppola F, Henriques B, Soares AM, Figueira E, Pereira E, Freitas R. Influence of temperature rise on the recovery capacity of Mytilus galloprovincialis exposed to mercury pollution. Ecol 
Indic. 2018; 93: 1060-1069.

56. Freitas R, De Marchi L, Bastos M, Moreira A, Velez C, Chiesa S, et al. Effects of seawater acidification and salinity alterations on metabolic, osmoregulation and oxidative stress markers in Mytilus galloprovincialis. Ecol Indic. 2017; 79: 54-62.

57. Cammen L, Corwin S, Christensen J. Electron transport system (ETS) activity as a measure of benthic macrofaunal metabolism. Mar Ecol Prog Ser. 2007; 65: 171-182.

58. Zeuthen E. Oxygen uptake as related to body size in organisms. Q Rev Biol. 1953; 28: 1-12.

59. Ablan MC. Total dehydrogenase activity reflects oxygen consumption rates in the giant clam Tridacna maxima (Bivalvia: Tridacnidae). Proceedings of a workshop held in conjunction with the 7th International Coral Reef Symposium; 1992 June 21-26; Guam,USA.

60. Smolders AJ, Lock RA, Van der Velde G, Medina Hoyos RI, Roelofs JG. Effects of mining activities on heavy metal concentrations in water, sediment, and macroinvertebrates in different reaches of the Pilcomayo River, South America. Arch Environ Contam Toxicol. 2003; 44: 0314-0323.

61. Dellali M, Gnassia Barelli M, Romeo M, Aissa P. The use of acetylcholinesterase activity in Ruditapes decussatus and Mytilus galloprovincialis in the biomonitoring of Bizerta lagoon. Comp Biochem Physiol C Toxicol Pharmacol. 2001; 130: 227-235.

62. Leiniö S, Lehtonen KK. Seasonal variability in biomarkers in the bivalves Mytilus edulis and Macoma balthica from the northern Baltic Sea. Comp Biochem Physiol C Toxicol Pharmacol. 2005; 140: 408-421.

63. Cravo A, Pereira C, Gomes T, Cardoso C, Serafim A, Almeida C, et al. A multibiomarker approach in the clam Ruditapes decussatus to assess the impact of pollution in the Ria Formosa lagoon, South Coast of Portugal. Mar Environ Res. 2012; 75: 23-34.

64. Vidal ML, Bassères A, Narbonne JF. Influence of temperature, $\mathrm{pH}$, oxygenation, water-type and substrate on biomarker responses in the freshwater clam Corbicula fluminea (Müller). Comp Biochem Physiol C Toxicol Pharmacol. 2002; 132: 93-104.

65. Bocchetti R, Lamberti CV, Pisanelli B, Razzetti EM, Maggi C, Catalano B, et al. Seasonal variations of exposure biomarkers, oxidative stress responses and cell damage in the clams, Tapes philippinarum, and mussels, Mytilus galloprovincialis, from Adriatic sea. Mar Environ Res. 2008; 66: 24-26.

66. Bocchetti R, Regoli F. Seasonal variability of oxidative biomarkers, lysosomal parameters, metallothioneins and peroxisomal enzymes in the Mediterranean mussel Mytilus galloprovincialis from Adriatic Sea. Chemosphere. 2006; 65: 913-921.

67. Orbea A, Ortiz-Zarragoitia M, Solé M, Porte C, Cajaraville MP. Antioxidant enzymes and peroxisome proliferation in relation to contaminant body burdens of PAHs and PCBs in bivalve molluscs, crabs and fish from the Urdaibai and Plentzia estuaries (Bay of Biscay). Aquat Toxicol. 2002; 58: 75-98. 


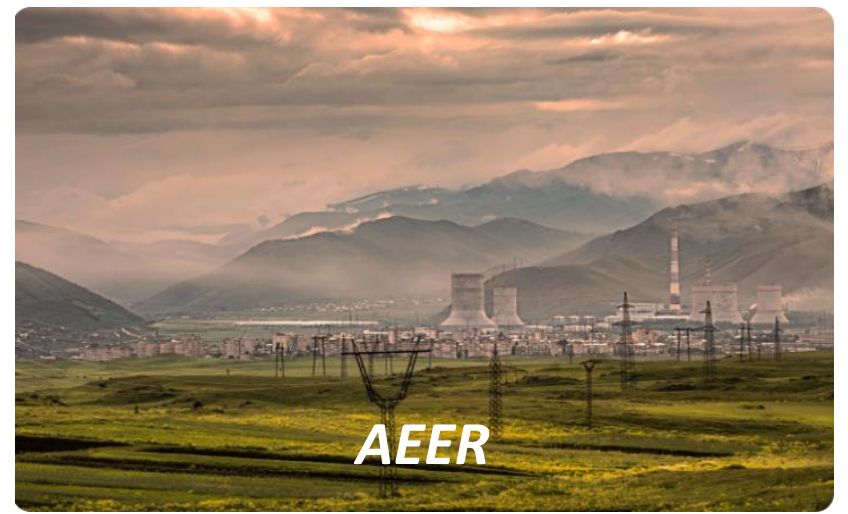

Enjoy $A E E R$ by:

1. Submitting a manuscript

2. Joining in volunteer reviewer bank

3. Joining Editorial Board

4. Guest editing a special issue

For more details, please visit:

http://www.lidsen.com/journals/aeer 